\title{
浅谈建筑玻璃幕墙工程中的节能措施与节能技术应用
}

华云洲

浙江省武林建筑装饰集团有限公司

DOI 号:10.18686/bd.v1i4.286

[摘要] 玻璃幕墙作为现代建筑重要外围护体系, 应用越来越广泛。随着低碳环保概念的深入, 必须加强提高其节能水 平, 基于此, 本文阐述了建筑玻璃幕墙工程中节能的必要性, 对建筑玻璃幕墙工程中的节能措施以及节能技术的应用进行 了探讨分析, 旨在提高建筑节能水平。

[关键词]建筑玻璃幕墙工程; 节能; 必要性; 措施; 节能技术; 应用

\section{1 建筑玻璃幕墙工程中节能的必要性}

基于玻璃材质独特的物理性能, 建筑能耗高以及温室 效应明显, 因此对建筑玻璃幕墙节能提出了特殊要求。玻 璃幕墙在应用过程中有更多的新兴技术和新型材料应用, 使玻璃幕墙的整体稳定性不断提高。但是玻璃幕墙在应用 过程中一直存在能耗较高的问题, 所以建筑玻璃幕墙设计 过程中, 必须选用合适的材料, 实行合理有效的控制措施, 将玻璃幕墙能耗降到最低。

2 建筑玻璃幕墙工程中主要的节能措施分析

2.1 合理应用玻璃幕墙断热型材。玻璃幕墙依照材料
的组成和结构方式分有四种:型钢骨架、铝合金型材骨架、 不露骨架构造和没有骨架玻璃幕墙。当中不露骨架构造和 没有骨架玻璃幕墙都是无金属框架，其幕墙的导热系数都 有玻璃自身与封条材料的功能来确定, 封条的材料大部分 都是密封胶与密封条。型钢骨架和铝合金型材骨架玻璃幕 墙由于使用金属框架, 容易产生冷桥与热桥, 所以选定金属 框架材料对于玻璃幕墙的节能具备特别关键的意义。现在 使用的新型断热金属框有很多名称, 但大部分都是在内外 两种高导热性的金属框料中间插人低导热性的隔离物,产 生有效断热层，阻断经过门窗框或窗扇型材散失热量的方 
法, 这就是所谓的断热型材。断热型材构造合理、牢固的结 合、高强度、刚性好、热阻大, 并且具备优良的隔声节能功 能、抗风功能与气密水密功能。早期多用于平开窗的断热 型材, 后来渐渐用于有框玻璃幕墙。随着的社会发展, 人们 生活水平的改善, 也愈来愈高档化的居住环境, 环保性, 新 型隔热保温型材这一新概念产品也从国外引进到我国。我 国从事铝加工设备的企业, 也能够开发出隔热断桥穿条设 备。新型断热铝型材经过连接穿条断桥, 能够连接氧化银 白料和彩色喷涂料, 砂面料和着色料的相连接, 使型材的 装饰感增加。

2.2 建筑玻璃幕墙的遮阳节能。有关数据显示, 在建筑 能耗中单层玻璃幕墙能耗大概占到 $40 \%$ 。在建筑物中, 尽 管太阳辐射、眩光和室内环境在遮阳的状况下获得改善室 内环境等起到必然的改善功能, 但是也会给室内通风和采 光形成一些影响。所以要结合详细的需求对遮阳体系实施 选择。如果依照地点实施划分, 系统能够分为内部遮阳和 外部遮阳; 如果依照遮阳方式来分, 则又能够分为垂直遮 阳、水平遮阳、挡板式遮阳和综合式遮阳。

2.3 使用双层中空玻璃处理。双层中空玻璃指用两块 玻璃相隔, 中间产生一单独空间, 能在这单独空间中充人 惰性气体, 从而让热交换减少, 起到保温隔热功能。或不充 人情性气体, 使空气自由流动实施通风, 双层玻璃相对于 单层玻璃同时又具备相对好的热绝缘功能。既可以自由通 风又可以起到相对好的保温隔热功能。双层中空玻璃幕墙 通常外层幕墙使用透过率大的单层透明玻璃幕墙, 像点式 幕墙等, 内层通常为中空玻璃幕墙。在 2 层幕墙工程中间 留有必然宽度的空气通道, 在通道的上下两端有进风与排 风设施, 实施空气交换。

\section{3 建筑玻璃幕墙工程中节能技术的应用分析}

3.1 智能技术的应用分析。智能玻璃幕墙是指可以根 据自身的调节和对外部温度的感应做出自动合理的调节, 使建筑内部的环境得到很好的改善, 让室内的环境跟适合 居住和办公。通常情况下.智能玻璃幕墙也是运用双层玻璃 幕墙为基础来设计的, 只是在科技上更先进了。智能化玻 璃幕墙可以通过网络进行对室内的光线、温度等等建筑配 套设施进行自动控制和调节与传统的玻璃幕墙相比较. 采 用智能玻璃幕墙后, 整个建筑的能耗大大降低. 这对玻璃幕 墙在节能环保中起到了重要的作用。

3.2 生态幕墙的应用分析。生态幕墙是随着建筑生态 化发展而发展出的新型产物, 其可以根据建筑的设计要求
以及功能要求改变生态和色彩, 并且以高新技术为核心, 以 生物气候缓冲层为关键点, 实现了资源的整合利用, 在一定 程度上缓解了环境污染问题, 为人们营造一个健康舒适的 生态建筑外围护结构。生态建筑和生态幕墙在三维空间中, 引人了时间的概念, 其在功能以及美学上都被赋予特殊的 含义, 人们将其称为 “四维建筑”, 即动静结合, 封闭和开放、 收玫和张开、空间与时间相融合, 使得建筑以及幕墙具有了 音乐韵律般的艺术感, 突破了传统建筑的板正印象, 为建筑 和幕墙设计注人了新的火力, 是对现代建筑幕墙的积极探 索, 也是一种技术以及设计理念的补充和拓展, 具有独立研 究和开发的价值。

3.3 光电幕墙的应用分析。光电幕墙是一种多功能的 太阳能光电玻璃幕墙, 其集合了发电、隔音、隔热、安全、装 饰等功能, 展现了现代建筑的智能化以及人性化特征。随 着人们日常生产生活对于电量需求量的不断增长, 发电成 本不断增加, 人们对于环境保护问题重视程度也得到提高, 因此, 很多国家开始推行太阳能屋顶计划, 并且提倡建筑物 自身生产能源的理念。光电模板简称为 PV, 是对多个太阳 能光电池进行组合加固处理, 并且将其嵌人特制的透明度 较高的低铁玻璃中, 二者通过背面导线连接在一起,形成了 一个光电模板整体。该技术发展较为完善, 其优点为在恶 劣环境下也可以正常工作, 抗外界干扰能力较强, 在臭氧、 酸雨或者是低温环境下, 光电模板的使用寿命仍然可以达 到几十年, 且外形美观。同时光电幕墙具有智能化特性, 太 阳能电池发电不会产生二氧化碳, 也不存在噪音污染问题, 可直接用于发电。由上述内容可以看出光电幕墙属于净能 源, 具有较好的相容性, 可以与环境和谐相处。

\section{4 结束语}

随着低碳环保概念的不断深人, 节能减排、保护环境已 经成为时代发展的必然选择。建筑玻璃幕墙是现代建筑的 主要结构, 在设计施工时, 必须从气、人文、经济和环保等多 方面进行考虑, 从而提高建筑玻璃幕墙的节能水平。

\section{参考文献}

[1]逸铭等.关于建筑玻璃幕墙的节能设计思考 [J].建 筑工程技术与设计,2015(03)

[2]窦智.建筑玻璃幕墙的节能设计研究科技 [ J]. 致富 向导,2014(21)

[3]梁忠.建筑玻璃幕墙节能技术研究 [J].建筑建材装 饰, 2014(15) 